\title{
Positive worry and negative hope: paradoxical perceptions of the experiences of Syrian refugee girls in Lebanon
}

\author{
Annie Dube ${ }^{1}$, Susan A Bartels $2,3^{*}$, Saja Michael ${ }^{4}$ and Valerie Michaelson ${ }^{3,5}$
}

\begin{abstract}
Literature on refugee well-being has largely focused on trauma, stress, and medical diagnoses. Less is known about how refugees adapt to their new contexts and experience hope for the future. This study examines the experiences of Syrian refugee girls in Lebanon through secondary qualitative analysis of SenseMaker ${ }^{\otimes}$ data. From a larger sample $(n=$ 1422), we selected self-interpreted narratives for which there was a discordance between the self-reported emotional tone and self-reported feelings for more in-depth analysis (final sample $n=25$ ). Our purpose was to better understand complex emotional responses to the challenging circumstances the girls experience. In our analysis, we identified three thematic categories related to the complex decisions girls face: education, marriage, and daily life as refugees. In the context of these three categories, we propose that understanding the complexity of emotional responses within a variety of intersecting spheres of life is a necessary first step in establishing realistic, relevant, and long-term community-led initiatives for displaced persons.
\end{abstract}

Keywords: Displaced, Girls, Lebanon, Refugee, Syria, Youth

\section{Background}

Syria has been engulfed in armed conflict since March 2011, resulting in an estimated 475,000 deaths and another 14 million people wounded or displaced (Syrian Observatory For Human Rights 2017). As a result of this crisis, Lebanon is currently hosting 1.5 million Syrians who have fled the conflict in Syria (including 997,905 million registered as refugees with UNHCR) (Government of Lebanon, United Nations 2018), and without the establishment of formal camps, most of these families live in makeshift structures within informal tented settlements or in overcrowded rented spaces (Global Communities - Partners for Good 2013). In 2014, approximately 70\% of Syrian refugees in Lebanon were recognized as poor by World Bank Standards (The World Bank 2015). With increasing debt and a growing reliance on food aid, many Syrian refugees continue to live in precarious circumstances.

\footnotetext{
* Correspondence: susanabartels@gmail.com

2Department of Emergency Medicine, Queen's University, Kingston, Canada ${ }^{3}$ Department of Public Health Sciences, Queen's University, Kingston, Canada Full list of author information is available at the end of the article
}

Lebanon is the highest per capita host of refugees in the world (Adaku et al. 2016), and this puts considerable strain on its already fragile economy and public service infrastructure (Cherri et al. 2016). Heightened demand for basic goods, services, and livelihood opportunities has become a source of tension between Syrian refugees and the host Lebanese community. As tensions rise, coping mechanisms, such as keeping Syrian women at home and Syrian children out of school, are increasingly employed. Escalating competition for basic necessities and for economic stability leads to frustration, scapegoating, and discrimination (Guay 2016).

Although there is no active armed conflict in Lebanon, Syrian families who have sought refuge there continue to face many challenges including obstacles to legal registration and the ongoing risk of deportation (Janmyr 2016), financial insecurity, lack of housing, inaccessible health care and schooling, and perceived threats of insecurity and safety risks (Bartels and Hamil 2014). This situation is not unique to Syrian refugees or to Lebanon. In fact, the existing refugee literature is replete with similar narratives for other refugees in different areas of the world (Kelley and Durieux 2004; UNICEF 2017). 
Children have been affected disproportionately by the Syrian crisis. With 39\% female-headed households and $61 \%$ male-headed, women and children account for $81 \%$ of the registered Syrian population, and $55.4 \%$ are below 18 years of age (Uppsala Conflict Data Program n.d.). Many children experience physical injuries, psychological stress, food insecurity, lack of basic health services, and/or being orphaned or separated from family (Bartels and Hamil 2014; UNICEF 2014; United Nations High Commission for Refugees 2013; World Vision International 2012). Financial insecurity requires that many Syrian children help to support their families by working (Bartels and Hamil 2014; United Nations High Commission for Refugees 2013) and are therefore not able to attend school. Within this context, Syrian girls face additional gendered risks of sexual harassment, exploitation, and gender-based violence (Human Rights Watch 2013; Spencer et al. 2015; Amnesty International 2016). Reports have also raised concern over increasing rates of child marriage among Syrian refugee populations (Abu 2013; Bartels and Hamil 2014; Spencer D, Care International 2015; UN Women 2013).

Despite these complicated milieus and having fled from war, insecurity, and persecution, many refugees find ways to adapt to their new contexts and emotional responses are not necessarily all negative. In fact, the range and complexity of emotional responses is typically underappreciated because of inherent biases that make it challenging for others such as researchers, journalists, and policymakers to identify where one could possibly see something positive in such difficult circumstances. Nevertheless, refugees and other displaced persons deserve the basic dignity of interpreting their own lives.

The current research seeks to understand the paradoxes or seemingly contradictory perceptions of their own lived experiences, particularly between girls, younger women, and older women as well as between mothers and non-mothers. In so doing, we prioritize participants' interpretations of their own lived experiences and recognize the emotional complexity of responding to challenging life circumstances.

We wondered if looking at these paradoxical perceptions would provide insight into how women and girls were coping, and even finding ways to thrive, in very difficult circumstances. Our method (described below) enabled us to invite each participant to tell a story, and then to interpret the feelings and emotional tone that they would associate with their shared story. By giving this aspect of "interpretive authority" (Ravitch and Mittenfelner Carl 2015) to the participants, this research informs and challenges our own assumptions and biases. While we recognize that we can never fully mitigate researcher bias, this approach did enable us to redistribute some of the power of interpretation back to the study participants.

\section{Methods}

This analysis uses data collected through a robust research tool called SenseMaker ${ }^{\bullet}$, developed by Cognitive Edge (2017). Based on complexity theory, SenseMaker helps to understand people's experiences in complex, ambiguous, and dynamic situations by using pattern detection software to identify common themes. Using a mixed methods approach, SenseMaker ${ }^{\oplus}$ leverages the "wisdom of the crowds" by collecting a large number of stories to give statistical power while still providing qualitative depth through the accompanying linked narratives. Because there are no responses that can be perceived as obviously better than others, SenseMaker reduces social desirability bias, and because participants interpret their own narratives using a series of pre-defined questions, the researchers' interpretation bias is also reduced. Though relatively new, SenseMaker ${ }^{\circledR}$ has emerged in recent academic literature as a valuable tool for data collection in studies related to ecology (Milne 2015), climate change (Lynam and Walker 2016), and global health (Bakhache et al. 2017). Our current analysis examines data from a larger SenseMaker ${ }^{\circledR}$ study conducted in July-August 2016 exploring the experiences of Syrian girls in Lebanon (Bartels et al. 2018).

\section{Participant recruitment}

In the broader study, a wide range of participants were recruited from three locations in Lebanon: the Greater Beirut area, Tripoli, and Beqaa. Criteria for inclusion included being age 13 or older and being part of one of the following subgroups: married Syrian girl, unmarried Syrian girl, Syrian mother, Syrian father, married man, or unmarried man (either Syrian, Lebanese, or Palestinian). Within each location, as long as inclusion criteria were met, a convenience sample of participants were approached in public spaces such as markets, cafes, public transportation stops, and depots and invited to participate in the study.

\section{Data collection}

The SenseMaker ${ }^{\oplus}$ survey was designed iteratively in collaboration with an experienced SenseMaker ${ }^{\circledR}$ consultant. The survey was drafted in English, translated to Arabic by a Syrian translator, and then back translated to English to check for accuracy. Translation discrepancies were resolved through discussion and consensus. The data collection team consisted of 12 interviewers: six were Syrian females (purposively selected to interview Syrian girls and mothers), three were Syrian men (to interview male Syrian participants), and three were Lebanese men (to interview male Lebanese participants). All interviewers participated in a 4-day training prior to initiation of data collection. Further details about the design and implementation of this study have been published elsewhere (Bakhache et al. 2017). 
The interview began by asking participants to choose one of three open-ended prompting questions ((a) Tell a story about a situation that you heard about or experienced that illustrates the best or worse thing about the life of a Syrian girl (under the age of 18) in Lebanon; (b) Provide a story that illustrates the biggest difference between life for Syrian girls (under the age of 18) living in Lebanon and life for Syrian girls in Syria; or (c) Suppose a family is coming to Lebanon from Syria, and the family has girls under the age of 18. Tell a story about a Syrian girl in Lebanon that the family can learn from). The prompting questions were designed through an iterative process, working with a SenseMaker ${ }^{\circledR}$ consultant, subject experts, and local partners to elicit honest and revealing answers. In response to these questions, participants were asked to share and then self-interpret an anonymous story about the experiences of Syrian girls in Lebanon. For the purposes of the survey, Syrian girls were defined as females below the age of 18 . Participants were then asked to interpret the experiences of the girl in the story by plotting their perspective between three variables (triads), using sliders (dyads), or plotting their perspectives on a graph (stones). As one of the interpretative tasks, each participant was asked to assign a positive or negative emotional tone to the story she or he had shared. A second interpretative task was to assign up to three emotions that reflected how the story made the narrator feel. Multiple-choice questions were used to collect demographic information and to provide context to the story. All interviews were conducted in Arabic in a private location. The stories that were shared were audio-recorded and then transcribed and translated to English. Data were collected using the SenseMaker app (Cognitive Edge 2017) on iPad Mini 4s and were uploaded to Cognitive Edge's secure server at the end of each interview day.

\section{Analysis}

A multiple-choice question in the SenseMaker ${ }^{\oplus}$ survey asked participants to choose up to three feelings associated with their shared story while another multiple-choice question asked participants to rate the emotional tone of their story from strongly positive to strongly negative. The sample of self-interpreted narratives analyzed here was chosen based on discordance between how participants responded on the feelings multiple-choice question and the emotional tone question. Specifically, we chose any narrative with (a) positive emotional tone (either positive or strongly positive) and at least one negative feeling (sad, angry, worried, disappointed, frustrated, or embarrassed) or (b) negative emotional tone (either negative or strongly negative) and at least one positive feeling (happy, hopeful, satisfied, good, encouraged, or relieved). We identified these participants as having "paradoxical perceptions" about the story they had shared.
Our first level of analysis involved selecting stories from participants who reported these paradoxical perceptions. This selection provided a sample of 29 self-interpreted stories with at least one feeling that was discordant with the reported emotional tone. Four of these participants were male, and since the study was primarily interested in the perceptions of women and girls, the four male participants were excluded, leaving a final sample of 25 participants. Participants were then subdivided into the following groups: (1) unmarried Syrian girls, (2) married Syrian girls without children, (3) married Syrian girls with children, and (4) older mothers with daughters. These 25 stories formed our initial transcript for coding.

Working independently, three researchers (AD, VM, SB) did the initial open coding of this transcript, each of whom reviewed the entire transcript closely. We used a process outlined by Saldaña, in which each researcher initially coded the data line-by-line enabling us to identify the diverse feelings, ideas, and experiences that emerged from each participant's shared story (Saldaña 2012). These initial, first level codes were generated directly from the text. After individual coding was complete, all three researchers reviewed the entire transcript together and agreed on a total of 157 first level codes, each of which represented a singular idea, feeling, or experience. This first level of coding enabled the researchers to gain a sense of the depth and complexity of the data.

In our second level of coding, initial codes were organized into groups, or categories, that helped to organize the stories about the experiences of Syrian girls in Lebanon. Three categories emerged from the codes: education, marriage, and daily life. Because of the inherent interconnectedness and dynamic relationship between each of these categories, the individual stories often fit into two or even all three of the categories, and stories were often placed into more than one.

Through discussion and consensus, the three researchers selected four salient stories from each category in order to illustrate the range of paradoxical perceptions that the participants' were experiencing. As we selected the four illustrative stories for each category, we were attentive to presenting a diversity of experiences and perspectives related to education, marriage, and daily life. This multi-level approach to analysis helped to provide an in-depth understanding of the research question while also grounding results in the data and in the participants' stories.

\section{Academic rigor}

Triangulation between researchers was a key part of the approach to analysis, and the three researchers (AD, VM, $\mathrm{SB})$ engaged in critical dialog around all aspects of story 
selection, coding, and analysis. Other strategies to enhance rigor included being sensitive to the literature base in this area and being purposeful about identifying what aspects of the data were most pertinent to the experiences of Syrian girls in Lebanon. As well, theoretical memoing was used in order to record additional insights and questions. Throughout the analysis, constant comparison helped to ensure that each code or story was considered in relation to previous and subsequent data and that the story was considered as a whole. Finally, an audit trail of all levels of coding as well as memos was kept.

\section{Ethics}

The Queen's University Health Sciences and Affiliated Teaching Hospitals Research Ethics Board approved this study protocol (Protocol \#: 6014981). All interviews were conducted in private, and no identifying information was recorded. Informed consent was reviewed in Arabic and was indicated by tapping a consent box on the handheld tablet. Since the study involved minimal risk, any requirement to have written consent was waived by the research ethics board at Queen's University. No monetary or other compensation was offered for participation.

\section{Results}

Description of study population

The final sample of 25 participants included unmarried girls $(n=5)$, married girls without children $(n=5)$, married girls with children $(n=6)$, and older mothers with daughters $(n=9)$.

\section{Paradoxical emotional tones and story feelings}

Our analysis is organized around three core categories that emerged during the second-level coding: education, marriage, and daily life.

Figure 1 summarizes the results and illustrates the complex range of emotional experiences related to the shared stories. Stories outlined with a solid line were identified by their narrators as having a negative emotional tone, and yet were associated with at least one positive feeling (such as feeling happy, hopeful, good, satisfied, or relieved). Conversely, stories outlined with

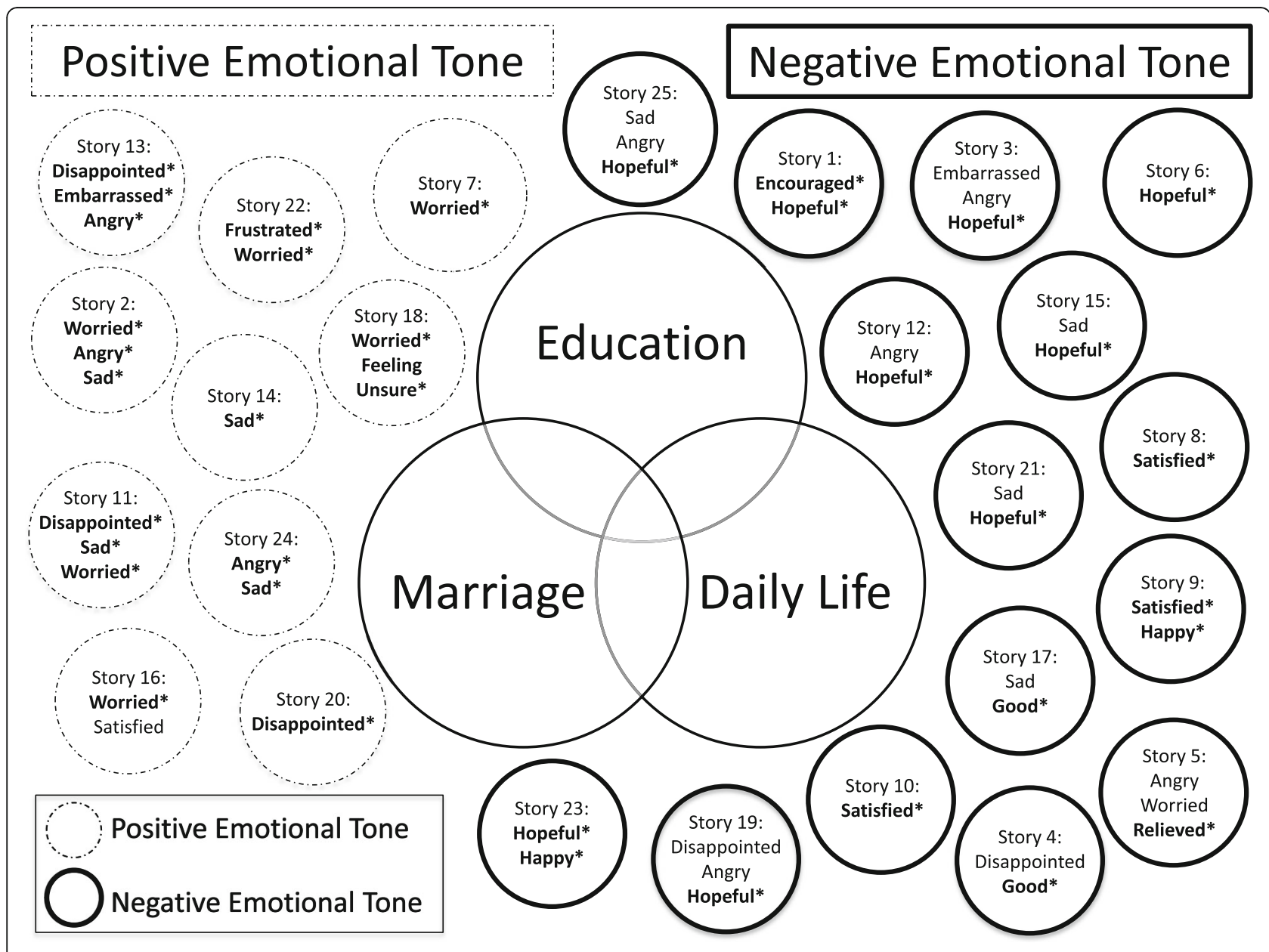

Fig. 1 Overview of all 25 stories displaying the three core categories and the reported emotional tone and feeling(s) attributed to the stories 
a dotted line were identified by their narrators as having a positive emotional tone, and yet were associated with at least one negative feeling (such as feeling worried, sad, angry, disappointed, or frustrated). All feelings that were discordant with the emotional tone (either $+/-$ or $-/+$ ) are marked with an asterisk.

All of these paradoxical perceptions of the narrators' experiences are organized around the categories of education, marriage, and daily life. Although we recognize that these experiences are inherently interconnected, organization of the stories into three distinct categories provided a systematic framework for understanding the experiences in each of these spheres of life. The three categories are presented as overlapping circles in a Venn diagram to reflect their overlap and interconnectedness. Additional details about the 25 stories are provided in Table 1 (Appendix).

\section{Category 1: Education}

Access to education or desire for education, either for the girl or for her children, was sometimes presented as a reason for hope or satisfaction, even when the story was described as having negative emotional tone. On the other hand, lack of education seemed to contribute to negative emotional tone and negative feelings such as sadness. Parents' reasons for not sending their daughters to school included concerns for their safety, financial vulnerability, or because their daughter was being married. Other barriers came from husbands, who prevented the girls from attending school, from lack of proximity to an appropriate school that matched her education and language levels, and from the girls feeling that they must stop school to work in order to support their families financially or to get married. Within the sphere of education, Fig. 2 displays four distinct stories that were selected to illustrate the paradoxical perceptions reported by the individual narrators.
Story 1: The difficulty of life In this story, an unmarried Syrian girl discusses the many hardships she faces living in Lebanon.

... since I am Syrian, they would want to give me more work than I can handle. They want to torture the Syrians that are arriving to Lebanon. . . I was going through psychological pressure. I used to arrive home crying. Due to this pressure, I was getting ill a lot, and I had an accident while I was working at home. I fell down. I was feeling annoyed, and I had a feeling of suffocation. I fell due to blood hemorrhage, and my immune system stopped working. .. I spent 3 days in the hospital in $[\mathrm{XXX}]$ region, and no one helped us. The medical expenses were very high. . . I went to Syria to be treated. . I have been living in Lebanon for 2 years, and the situation is still the same; it is work, work, and stress. . I work in a kitchen. The owner always insults us, and he makes it very clear that he is being generous with giving jobs to Syrians. My work hours are from 8:30 am till 6:00 to $6: 30 \mathrm{pm}$. I should be standing all the time. Whenever I sit down for a little while, the owner would yell at me to go continue my work. I would cry a lot, especially from the insults. "You, Syrians, are coming to rob us" or "You, Syrians, are coming to torture us". These curses and insults bother me a lot, and I'd feel choked, then I'd cry. . . I do not think of getting married anytime soon. I want to continue my education and my dream. So I do not think of marriage. I have the freedom to decide, my parents gave me this freedom. They will not make me do anything that I do not want to do.

Despite these hardships, this girl was given the freedom to continue her education by her parents. While she described her story as having a negative emotional tone, she also said that the story made her feel encouraged and hopeful.

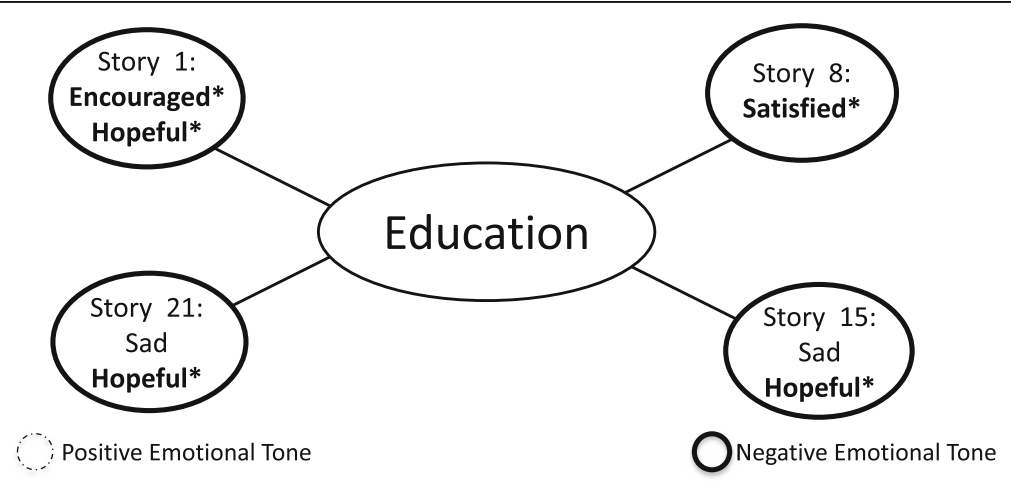

Fig. 2 Paradoxical experiences related to education 
Story 8: Knowledge is power In this next story, a married Syrian girl describes the challenges of accessing education in Lebanon and expresses how she has lost all hope of continuing her schooling.

Before the war, I was enrolled in school and reached the 7th grade. I wanted to continue my education; I had this idea in mind. My parents encouraged me to continue knowing that education will help me a lot. When the war started, we were displaced within Syria to a village that had an elementary school only. . . My only option was for someone to take me to the nearby village, where we would need more than half an hour to reach it, and I did not have anyone to take me. So I was obliged to stay at home. I stayed 2 years at home. Until I became 16 years old. According to the traditions and norms when a girl reaches 16 years, she should get married. I married my father's cousin. I have been married for a year and 7 months now. Living and staying in our first home in Aleppo would have been the best case for me. I wanted to continue my education. I wish I were able to continue my education. I have five sisters, three of whom are younger than me and left their education as well. My nine-year-old sister does not know how to read the numbers from zero to ten. They are all without education. I wish I could have had the chance to continue my education and have a job later. When I got engaged, I did not want to get married. But I was compelled to, since I would have gotten married eventually. I have lost all hope in continuing my education.

While the narrator interpreted this story about herself as having a negative emotional tone, she also reported that the story made her feel satisfied.

Story 15: Intense sadness or deep grief Here, a married Syrian girl with two children of her own explains how the events in her life have compelled her to highly value her children's education.

I am 20 years old, and I have a 6-year-old son and a 10month-old daughter. We were displaced to Lebanon 5 years ago. At first, we went through some difficult and humiliating circumstances. . . It took us a while until things got better. . . His [husband] brother found a job for him in a restaurant in the [XXX] area. My parentsin-law helped us a lot, and thanks to God we made it through the worst. I wish I could enroll in a sewing workshop or any other workshop, in order to learn something new and have fun. We do not do anything, and we do not know anyone. So attending any workshop with other women would help me a lot. But I did not have the chance to do so. Any woman would like to work or do something, but what can we do? We cannot do anything. My mom is deceased, and I live with my father and brother. It was arranged for me to marry my cousin. I got married very early. My dad forced me to stop school in 6th grade and to get married. I got married really early, and I suffered a lot during my childhood. How would I explain this; I do not have a mother, and all my siblings are married. I suffered a lot with my marriage. I lived at my parents-in-law's place. I could not go out at all; I wish I could have continued school but I did not have the chance. That is why now I put a lot of effort into my children's education; I want them to be educated. I do not want my children to go through what I had to go through. I'd like for them to go out a lot, to be educated, and to have a social life. . . But what can we do about it? We cannot do anything, and thank God for what we have.

The story was interpreted by the girl as having negative emotional tone and making her feel sad. Paradoxically, and perhaps counter-intuitively, she also reported that the story made her feel hopeful.

Story 21: Educational suffering In this story, a Syrian mother describes a family that had a unique educational opportunity after moving to Lebanon.

The story is about the concierge. . In Syria, his daughter was in the 6th grade, but when they arrived to Lebanon she was down placed to either the 5 th or the 4th grade. .. when his daughter attended school here, she went through a lot of difficulties. In $[\mathrm{XXX}]$ the whole curriculum is in Arabic, but here the curriculum includes studying in the English language as well. His daughter could not cope with the educational system here. Therefore, they placed her in either the 5 th or the 4th grade instead of the 6th. The father hired a teacher for his daughter to help her with her schoolwork. This displacement may have given the daughter a chance to continue her education. Since, in the countryside of Aleppo her parents would have arranged for her to get married in a couple of years. Also, in the countryside of Aleppo seeking education is really hard.

While she identified the story as having a negative emotional tone, she also reported that the story made her feel hopeful.

\section{Category 2: Marriage}

The complexity of marriage is illustrated through the diversity of stories shared by the participants. Many families felt pressured into marrying their daughters early as a means to protect them and to secure the girls' economic futures. Stories about marriage with positive 
emotional tones described situations in which the girls reported being satisfied with their spouses, appeared to be in healthy, loving relationships, and/or reported experiencing greater freedom and opportunity than they had as unmarried girls living with their parents. Stories about marriage with negative emotional tones described experiences of intimate partner violence as well as abuse by the husband's family. Illustratively, one girl who had been forced to marry her husband (story 5) described her marriage as "living together like two strangers" and also reported being blamed for her own feelings of being "miserable."

Stories from older mothers sometimes illustrated feelings of helplessness with regard to decision-making around their daughters' marriages, and others expressed regret that their daughters had married prematurely. One Syrian mother talked about how "young girls are entitled to live through their full childhood. They should play, learn, and live freely; they shouldn't carry a load that is greater than anything they can handle" (story 22). Another told the story of a minor who was married, but was not ready for either marriage or for having children. She described this as "really wrong" (story 11). And yet, each one of these older mothers associated a portion of this story with something positive. Figure 3 illustrates the paradoxical experiences related to marriage.

Story 16: I love my life A married Syrian girl tells a story about her new life in Lebanon. She explains the difficulties she faced balancing her education and job and how she met her husband. Despite marrying at a young age, the participant describes a positive relationship with her husband and her in-laws.

... In Syria I did not use to work, but when I arrived to Lebanon I was obliged to work in order to support my family. I also applied to continue my education. I wanted to be enrolled in the literature curriculum, but the choice is not up to you, they enrolled me in the scientific curriculum. I decided to try to work and study at the same time. I decided that if I found it really hard to keep up with both, I would leave work to concentrate solely on studying. The curriculum started, but I only attended for 3 weeks. The principle interfered in what we had to wear, and he decided that girls and boys should not socialize together. I did not attend my classes anymore and continued to work... The best thing that happened to me was that I met my husband here. His family is my family now. . We met each other here, and we got married. He is a great person, and we love each other a lot. And his parents love me a lot. When I delivered my child, they treated me as their daughter.

The girl indicated her story had a positive emotional tone and associated it with feelings of satisfaction and worry.

Story 10: Oppressed from everyone In this narrative, a married Syrian girl shares her story about being forced into a marriage that turned out to be abusive.

I will tell my story. One of my father's relatives wanted to marry me. I did not accept at first, then they convinced me that he is good man, and I accepted. When I got married, we had a fight on our first day together in our house. We fought constantly. Then I fought with his parents. My husband, his mother, and his uncle beat me. Even their guests would beat me. I suffered a lot when I lived with them. I neither ate nor drank anything, and I always stayed alone. They would yell at me and insult all the time. I stayed there for 20 days, and I could not take it anymore. I returned to my parent's place, and they told me that everything will be okay after my husband and I reconcile. When I told them I do not wish to reconcile things with my husband, they started to beat me as well. They took me to a clerk to check if I was possessed or something. I suffered at my parents' house and at my parents in law's house. I cried all the time. They told me

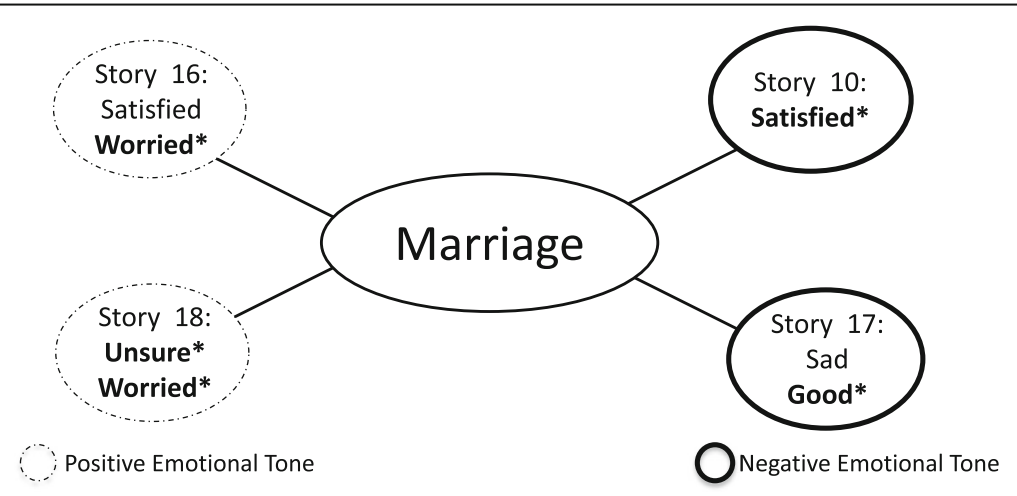

Fig. 3 Paradoxical experiences related to marriage 
that I am divorced now and they got all my stuff back. But I do not believe them. I have this feeling that they are not being honest. I am afraid of going back to his place. I am not able to believe my parents, since they got water some holy water in order to treat me. They are suspicious that I am possessed or that someone has put a spell on me. And I am afraid that they are searching for treatments just to send me back to his place. I fear him. I hate him. I feel he is the devil, and I do not stand his sight. I always tell my parents that I would kill him if I saw him in front of me. I suffered a lot with him. I hate him.

While she described her story as having a negative emotional tone, she also associated it with the feeling of satisfaction. We can only speculate here, but this feeling of satisfaction may stem at least in part from being out of a relationship that she experienced as physically and emotionally dangerous.

Story 17: Education is a child's right In the next story, a Syrian mother discusses the many hardships her and her family faced in Lebanon and talks about feeling helpless when her husband decided to take their daughter out of school and to marry her at a young age.

When we arrived in Lebanon, my daughter wanted to continue her education. They said it is not safe for her to go and wander freely. So my husband told her that she could not continue her education. He feared for her safety. She got mad, and for 2 years she rebelled on both of us. She did not talk to us, and she always says that this is our fault. We told her about other girls her age that were obliged to do the exact thing she went through, but they did not keep the grudge that she kept. Then we got her married. She wanted that. She expressed that it would be more comfortable for her to get married; better than sitting around with nothing to do. If she got married, she could go out with her husband at least. . . I wanted her to continue her education, I really did. But I could not do anything to help her get what she really wanted. My husband feared for my daughter's safety a lot. Contrary to a boy, she cannot be wandering around freely in such unsafe situations. We do not know exactly what it's like to be in Lebanon, and we hear that there are a lot of conflicts and disputes taking place. So he feared for her, and he would not let her go. After a while she forgot all of it.

The story was interpreted as having a negative emotional tone and associated with feelings of sadness and good feelings.
Story 18: Fate and destiny The final story about marriage is shared by a Syrian mother whose daughter was married at the age of 15 . The mother felt this was too early to get married and regretted accepting the marriage proposal.

My daughter got married when she was 15 years old. She was very young. When they visited us to marry our daughter to their son, we told them that she is still young. They responded that they usually permit a one-year engagement. So we accepted. She got engaged for 1 year, and after that she got married. She was still young, and her husband is young as well. After she got married, she got pregnant and delivered a baby girl. You'd feel that this baby is her sister not her daughter. You'd also feel that the couple is still very young and childish like. I regret accepting to this early marriage.

The mother indicated that her story had a positive emotional tone, and yet, she associated it with feelings of worry and uncertainty.

\section{Category 3: Daily life}

The paradoxical experiences in this category focus on the challenges of living in Lebanon after forced displacement and include difficulties securing documentation of refugee status, financial stress, and safety concerns. Difficulties getting legal documentation in Lebanon were a common issue described by the participants in our sample; without it, children were not able to attend school and couples were not able to register their marriages. Another important issue was financial constraints, which limited access to health care and formal education. One participant described living in a camp because there was no money for a room and describes herself as "suffocating" (story 12). Although being in Lebanon relieved the immediate dangers of armed conflict in Syria, safety was still a notable concern, particularly for women and girls who seemed to be at high risk for harassment and sexual abuse. Despite the difficulty and adversity described in these stories, each one also included an aspect of positivity. Figure 4 outlines four stories selected to illustrate the paradoxical experiences related to daily life for Syrian refugees in Lebanon.

Story 24: My story The following story is from a Syrian mother who talks about the hardships faced by a family in the neighborhood and how they came together as a family to support each other.

Our neighbour got married when she was 14 years old. Her father was arrested and killed in Syria. The family had no support at all. So her mother was 


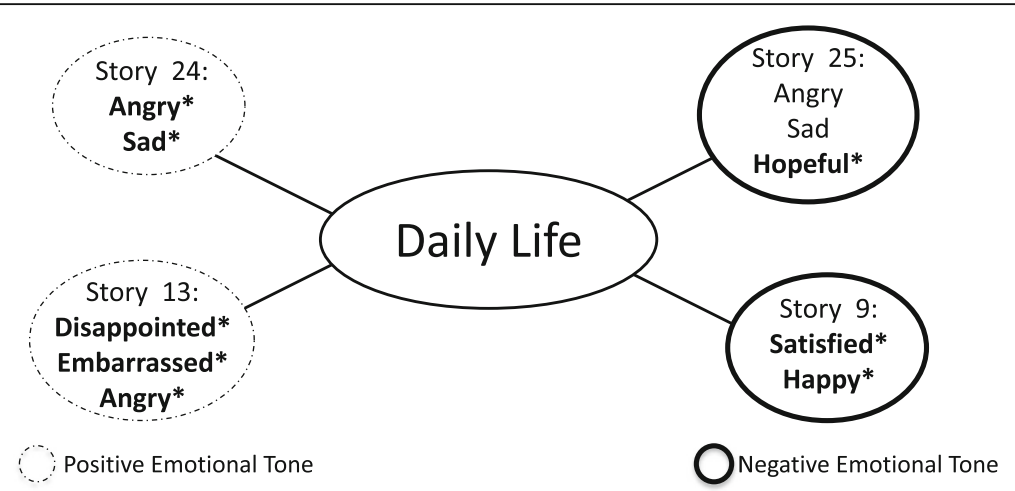

Fig. 4 Paradoxical experiences related to daily life

compelled to permit her early marriage. The mother cannot support her family anymore. Furthermore, her younger sister left school and started working to help in supporting her siblings.

She indicated that her story had a positive emotional tone and selected feelings of sadness and anger.

Story 25: Foreignness The following story shared by a Syrian mother discusses issues related to documentation and how they impeded both her children's enrolment in school and the registration of their marriages.

I have five daughters and a son. Two of my daughters were very young when we were displaced. They were in the 6th and 7th grade. We left Syria while they were registered on my legal document only. I wasn't able to either get their identification cards or to enroll them in any school. Now, they are 17 and 18 years old. They got married recently, and they do not have any legal documentation. So, they were not able to register their marriages at the embassy. I cannot go back to Homos to reorder their papers. At home, I have a 14-year-old daughter that cannot enroll into any school due to the situation in [ ] Camp and due to our financial situation. Even the legal documents of my son-in-law were lost. They lost his papers in the United Nations when they were renewing them. So now, he has no legal papers at all. The most important things now are my daughters' personal identification papers and registering their marriages.

The story was described by its narrator as having negative emotional tone and was associated with feelings of sadness and anger. And yet, the narrator also described the story as making her feel hopeful.

Story 9: A sad story A married Syrian girl discusses the many hardships she has faced, including stopping school, early marriage, and displacement to Lebanon. She describes some of the challenges of life as a refugee but notes that at least the stresses of war are relieved in Lebanon.

I used to be enrolled in school, but then after the armed conflicts and tough circumstances, I left school. My schoolmates were being kidnapped. We were running away on daily basis, and we had no home anymore. My uncle's family and us sought refuge on the streets under the trees. Our life did not have any meaning anymore. My father wanted to make sure his daughter was safe, so he married me off. After I got married, my husband and I prepared all our legal papers and passports, and we displaced to Lebanon. Here we are relieved from the stress of war. We do not hear airplanes or bombings. We are relieved from running away every day, from the missiles noise, and from the aircraft's hits. Here, we are psychologically relieved. My parents-in-law and my parents displaced to Lebanon as well. But even though we are relieved from the stress of war, we are still living in a tough situation. There is not any chance of education, and finding a good job is very hard. My husband arrives with back pain and headaches every day.

This participant indicated that her story had a negative emotional tone and was associated with feelings of happiness and satisfaction.

Story 13: Harassment of Syrian girls In this last story about daily life as a refugee, a married Syrian mother describes her experiences of harassment in Beirut.

I am 22 years old now. I was married at 17 while I was still in school. I took my Baccalaureate and did not continue my education. After I got married, I had a son. I was married in 2011, and we were displaced to Lebanon 2 years ago. Now I am living here with my 
husband and son. When I go to Beirut, the taxi drivers harass and cat call any women passing by. Regardless if the woman was with her child, married, or pregnant; they would harass any woman. Some of them would talk some very dirty words, and they would not differentiate between an unmarried woman and a woman with her children. When she is walking with a man, they would not dare to talk anything. But if a woman is walking alone, they would harass her a lot.

She identified the story as having positive emotional tone and associated it with feelings of disappointment and embarrassment.

\section{Discussion}

Overall, these 25 stories shed light on the seemingly contradictory perceptions of the experiences of Syrian girls who have been displaced to Lebanon, particularly around education, marriage, and the challenges associated with daily life as refugees. In each of these stories, there was a discordance between the reported emotional tone and feelings associated with the story, which may reflect the paradoxical nature of the girls' experiences in Lebanon. Through the participants' own paradoxical interpretations of their stories, we gain a nuanced understanding of the complex emotional responses to the difficult circumstances faced by the girls and their families, and insight into how young women and girls cope, and even find ways to thrive, under very difficult circumstances that might be easy to overlook.

\section{The value of interpreting one's own life}

Within each of the three categories, we presented four unique stories, each illustrating the complexity and diversity of the challenges that displaced Syrian girls have to navigate. The stories about education included a wide range of experiences. In story 1 , even though the girl reported workplace discrimination and serious health issues, which may explain the associated negative emotional tone, she also described her dream of continuing her education and the freedom her parents gave her to make her own choices. This is illustrated in her words "They won't make me do anything that I do not want to do." Having this agency around her own life may explain the feelings of hope and encouragement she experiences in the face of the adversity. The girl in story 8 was not given the opportunity to finish her education, which may explain the negative emotional tone she ascribed to her story. And yet, for her, even though she clearly states that when she got engaged she "did not want to get married" and her "wish" was to continue her education, she is still able to report feeling satisfied. The phrase "since I would have gotten married eventually" suggests an acceptance of married life as an inevitable part of her future and also speaks to gender norms, expectations, and stereotypes around girl/women's roles in society. In story 15 , the negative emotional tone may be explained by the losses experienced by the girl: her mother's death, the war, being forced to leave school, the suffering in her marriage and childhood, the financial stress as a refugee in Lebanon, and her lack of freedom to socialize. Despite all this adversity, her sense of hope seems to stem from a desire and determination to create a better life for her children by allowing them to pursue an education. She is also very thankful for what she has, even though she has encountered many hardships. And finally, similar to the other three narratives, the negative emotional tone of story 21 seems to result from the challenges faced in Lebanon, particularly with respect to the different educational systems. However, unlike the other stories, this girl had an educational opportunity that probably would not have existed in the Syrian countryside, thus creating hope for her future. This paradoxical experience appears to derive from the hope associated with a unique educational opportunity in the midst of the many challenges associated with forced displacement. Education was valued by each of these girls, and for three out of four of them, marriage was seen as inevitable. But even having accepted the end of her education to get married for herself, it is interesting to note that the girl in story 15 still held a strong hope for her children "not to go through what [she] had to go through" and to have access to education.

The four stories about marriage, equally, held paradoxes that might have been easy to miss were it not for the girls' and women's own interpretations of their stories through SenseMaker's innovative interpretation questions. Illustratively, in story 16, from the girl's perspective, the marriage is happy, potentially explaining the positive emotional tone and the feeling of satisfaction. The worry associated with the story could arise from having to leave school early and from her family's financial stress and the hardships associated with life as a refugee. In story 10, a girl experienced extreme suffering both at the hands of her husband and his family as well as her parents. After hearing the story, we might not readily predict that she would associate it with being satisfied. Could this positive feeling in the midst of a very distressing situation result from her ultimate divorce and from being free of the abusive environment? In story 17, a mother identified as feeling sad, possibly about her sense of helplessness of not being able to keep her daughter in school. The good feeling attributed to this story may arise from the fact that the daughter eventually wanted to marry and that she ultimately had more freedom to leave the house as a married woman. This created a paradoxical experience for the Syrian mother; although her daughter was forced to stop her education to marry at an early age, the marriage was 
able to provide the girl with more freedom than she had when she was single. Story 18 was similarly told by a mother who worried that her daughter had married too early, before she was ready to be a mother. Even though she identified the story as having a positive emotional tone, she also described the couple as "still very young and childish like" and expressed her own regret in accepting this early marriage.

During the analysis, we observed a striking difference between the attitudes of many of the young girls towards marriage and the attitudes of many of the mothers. While numerous girls saw early marriage as inevitable and as a way of accessing more freedom and protection, several of the older mothers expressed concern about the consequences of early marriage and advocated for girls not to be married at young ages. It is important to note, however, that the girls who were able to participate in the study were more likely to have the freedom to engage with society in the first place, which likely introduced bias to our sample. Although some participants shared their own experience that marriage brought more freedom, we cannot conclude that that is a more general experience. It may be true that the married girls who were forced to remain in their households were not able to participate in this study because of their limited freedom, and we do not want to imply that marriage is always a way of accessing more freedom and protection. In contrast to the girls, many of the mothers held the perspective that despite the potential benefits, they wanted their daughters to be able to live their full childhoods without carrying the responsibilities of marriage until they were ready and choose to do so.

The stories related to daily life also held many paradoxical emotional experiences. In story 25, the negative emotional tone and feelings of sadness and anger appear to stem from challenges around obtaining legal documentation and its associated consequences. The feeling of hope may be that things will be better once the legal papers are secured, as this was the biggest concern that was voiced. The paradox arises from the mothers feeling hopeful despite the challenges surrounding documentation and their life in Lebanon. In story 24, survival after the father's death seemed to depend on one daughter being married while the other left school for work to help support the family. The story's associated feelings of anger and sadness may be about the circumstances that left this family so desperate in the first place. Could the positive emotional tone relate to the very success of finding ways to survive in the midst of dire circumstances? In story 9 , the negative emotional tone may be attributed to the girl in the story having to leave school and the ongoing challenges faced in Lebanon. Feeling satisfied and happy may arise from no longer living in an area affected by active armed conflict and being relieved of the stresses associated with war. And finally, in story 13, her husband's protection from the harassment faced in Lebanon may have accounted for the positive emotional tone the girl attributed to her story. The anger, disappointment, and embarrassment may stem from the actual experiences of harassment.

The danger of interpreting these complex stories without the perspectives of the participants themselves is at least twofold. First, having a voice in matters that concern one's own life is a basic right protected by the Convention on the Rights of the Child (UN Office of the High Commissioner for Human Rights 1989), and there is a basic dignity that comes with having authority in interpreting one's own life situation. And second, the people who are best positioned to interpret these complex experiences are not the people watching from a distance, but the people who are experiencing them. Without the perspectives of those living through the situation, the insights and nuances that are essential for developing realistic and relevant programming and support for Syrian refugees in Lebanon will be missed. Notably, early marriage was sometimes perceived to be the best choice out of options that were even worse. In retrospect, the older parents seem very cautious about girls going into early marriage, even though it may seem like the best short-term solution. If there were more resources available for girls, they likely would not be forced to choose between premature marriage, education, harassment/abuse, and their own economic security and/or that of their family. Before displaced women and girls can receive support and programming to meet their needs, their experiences need to be heard and understood. In fact, we would argue that it is time to move beyond listening and to also focus on fostering beneficiaries' roles as active agents of change by addressing the hierarchies in program design and implementation.

Many of these women and girls have been forced to draw on internal strengths and non-traditional sources in order to navigate a precarious and even dangerous environment. It is possible that these types of strengths are supported and even fostered within the subcultures in which these women live and that these same strengths may continue to serve them well as they create change for themselves and their children. As others have found in various contexts (Bender et al. 2007; Hou et al. 2016), it would also be valuable for humanitarian actors to focus on a "strengths perspective" and to implement programs that build on the resilience of displaced individuals, empowering them to maintain some control over their own lives.

Within each of the individual narratives, it may be hard for those who view the stories through an outside world lens to see how the narrators could find positive in the experiences they described. And yet, in their work 
with refugees, Brough et al. conclude that the coexistence of positive and negative aspects of horrific events is not paradoxical but rather represents the true reality that victims have faced, as a part of human nature (Brough et al. 2013). From this perspective, it is important to note that the seeming paradoxes presented here arise at least partially from the limited lens through which we approach understanding these experiences. We would agree with resilience expert, Michael Ungar and his colleagues, who have called for a new wave of resilience research "that is sensitive to culturally-embedded definitions of positive development in both Western and non-Western countries" (Ungar et al. 2008).

\section{Comparison and contrast with existing literature}

Historically, much of the dialog on refugees has focused on trauma, and the refugee experience has often been conceptualized within a western, medicalized framework. This discourse has more recently been challenged, however, and our current study fits into a broad and emergent literature base that is interested in a more complex, human and multidimensional experience of refugees. Illustratively, a study that is similar in intent and findings to our own work is by Brough et al. (2003) with immigrants from diverse ethnic backgrounds. These researchers caution about focusing on biomedical outcomes such as post-traumatic stress disorder (Brough et al. 2003), and in their salutogenic paradigm, they report on the extraordinary adaptive capacity of Burmese refugees in Australia (Shakespeare-Finch et al. 2014). Brough et al. also interpreted narratives of social suffering and hope as representing complex fields of meaning from which Burmese refugees interpret their difficult pasts and hopeful futures (Brough et al. 2013). This kind of focus on salutogenic approaches that promote the coping abilities of individuals and communities may also be useful in the context from which our research emerged. This does not, however, take away responsibility from policy makers and service providers to work to improve the lives of girls; it does, however, lead to more active agency and choice in one's own life.

Other studies, too, have observed similar demonstrations of adaptation and resilience to those identified in our study, despite extremely challenging circumstances. Looking at the experiences of Sudanese refugees in Australia, researchers concluded that most refugees were in fact succeeding in adapting to their new environments, in spite of their past traumatic experiences and the difficulties they faced in their new lives (Shakespeare-Finch and Wickham 2009). Similarly, in her work with Congolese refugees, Tippens focuses on understanding how individuals coped with stressful situations and on identifying factors that facilitated or undermined their resilience. She found that religious faith, "borrowing networks," and compartmentalizing the past from the present all mitigated the stress associated with scarcity of material goods, insecurity, and emotional distress (Tippens 2017). The first two stressors identified by Tippens (financial/material needs and concerns about insecurity) were also prominent in our current analysis.

As we have done, other researchers have also sought out alternative methods to better reflect the lived experiences of refugees. For instance, Pearce et al. used Photovoice to reconstruct non-Western-centric notions of resilience among South Sudanese refugees in Canada and in doing so called for additional research that would leverage the contextualized experiential knowledge of diverse populations (Pearce et al. 2017). Because SenseMaker ${ }^{\circ}$ does not ask direct questions but rather relies on open-ended prompts to elicit stories about a broader topic of interest, the resulting narratives emerge from the broader landscape of experiences helping to contextualize the stories' events within the everyday lives of narrators. In doing so, we believe the complexities of lived experiences are presented in a more natural manner that allows the participants' voices to be heard.

\section{Strengths and limitations}

This study has several limitations. First, despite considerable effort to collect narratives from a diverse group of participants, the sample was not representative and thus results cannot be generalized to the wider population. More marginalized, harder to reach, or mobile families may have been underrepresented, and girls less than age 13 were not included in the study. Additionally, SenseMaker ${ }^{\circ}$ narratives are relatively short in comparison to more traditional qualitative interviews, and therefore, the shared stories sometimes lacked the detail and richness typically found in in-depth interviews. We also recognize that as researchers, our own biases are inevitably present in this analysis, and as such, we have tried to propose a number of possible interpretations to explain the paradox within individual stories. The study has several notable strengths including the self-interpretation of shared stories, which placed the "interpretive authority" with the participants. This helped to reduce researcher bias and allowed the participants' own perceptions to come to the forefront of our analysis. The lack of direct questioning also allowed participants' perceptions about positive and negative experiences to emerge from the broader landscape of the everyday life of Syrian families. Lastly, interviews were conducted in Arabic, and researchers continuously checked interpretation with local stakeholders, thus allowing for participants to fully communicate their stories and feelings. 


\section{Appendix}

Table 1 Story number, participant category, reported feelings, and emotional tone

\begin{tabular}{|c|c|c|c|}
\hline Story number & Category & Reported feelings & Emotional tone \\
\hline 1 & Unmarried girl & Encouraged, hopeful & - \\
\hline 2 & Unmarried girl & Angry, sad, worried & + \\
\hline 3 & Unmarried girl & Embarrassed, angry, hopeful & - \\
\hline 4 & Unmarried girl & Disappointed, good & - \\
\hline 5 & Unmarried girl & Angry, worried, relieved & - \\
\hline 6 & Married girl without children & Hopeful & - \\
\hline 7 & Married girl without children & Worried & + \\
\hline 8 & Married girl without children & Satisfied & - \\
\hline 9 & Married girl without children & Satisfied, happy & - \\
\hline 10 & Married girl without children & Satisfied & - \\
\hline 11 & Married girl with children & Disappointed, sad, worried & + \\
\hline 12 & Married girl with children & Angry, hopeful & - \\
\hline 13 & Married girl with children & Disappointed, angry, embarrassed & + \\
\hline 14 & Married girl with children & Sad & + \\
\hline 15 & Married girl with children & Sad, hopeful & - \\
\hline 16 & Married girl with children & Worried, satisfied & + \\
\hline 17 & Older mother with daughter(s) & Sad, good & - \\
\hline 18 & Older mother with daughter(s) & Worried, feeling unsure & + \\
\hline 19 & Older mother with daughter(s) & Disappointed, angry, hopeful & - \\
\hline 20 & Older mother with daughter(s) & Disappointed & + \\
\hline 21 & Older mother with daughter(s) & Sad, hopeful & - \\
\hline 22 & Older mother with daughter(s) & Frustrated, worried & + \\
\hline 23 & Older mother with daughter(s) & Happy, hopeful & - \\
\hline 24 & Older mother with daughter(s) & Angry, sad & + \\
\hline 25 & Older mother with daughter(s) & Sad, angry, hopeful & - \\
\hline
\end{tabular}

\section{Conclusions}

Within the context of the Syrian crisis, female children are disproportionately vulnerable. They face gendered risks of sexual harassment, exploitation, and genderbased violence, and as many of the stories in this study illustrate, they are often forced to make difficult decisions in order to survive. Choices (or lack of) between marriage and education are central in navigating this context. And yet, even in the midst of these complicated milieus, some refugees find ways to adapt to their new context and to feel encouraged and hopeful. In this study, our goal was to understand the paradoxes or seemingly contradictory perceptions about the experiences of Syrian girls in Lebanon by using Sensemaker ${ }^{\circ}$ to gain nuanced insights into the girls' and woman's own interpretations of those experiences.

While education for girls and early marriage may be rightly considered public health priorities, before these problems can be "fixed," the complexity of the spheres of life that Syrian girls in Lebanon navigate needs to be heard and understood. The lived experiences of displaced persons need to take precedence-as the assumptions, biases, and limited experiences of external researchers, policymakers, journalists, and others limit the ability to truly understand the circumstances. With an improved understanding of these lived experiences, realistic, relevant, and sustainable strategies can be identified, designed, and implemented to reflect the complexities of lived experiences of refugees.

\section{Abbreviations \\ UN: United Nations; UNICEF: United Nations International Children's Emergency Fund}

\section{Acknowledgements}

The authors are indebted to all participants who shared their stories and perspectives. We are grateful to ABAAD Resource Center for Gender Equality, including team leads Katia Ghandoura, Clara El Warrak, and Salma Atwi. We also thank the interviewers as well as $\mathrm{X}$ for their dedication and hard work.

\section{Funding}

This work was supported by the Sexual Violence Research Initiative and the World Bank Group's Development Marketplace for Innovation on GBV Prevention (in Memory of Hannah Graham). 


\section{Availability of data and materials}

The dataset analysed during the current study are available from the corresponding author on reasonable request.

\section{Authors' contributions}

SB conceived of the original SenseMaker ${ }^{\oplus}$ study, helped design the SenseMaker ${ }^{\oplus}$ survey, and trained the interview team. SM directed field implementation and oversaw recruitment of interviewers and team leads. VM conceived of this analysis. AD, VM, and SB completed the data analysis. AD drafted the initial manuscript with all authors contributing to writing. All authors read and approved the final manuscript.

\section{Competing interests}

The authors declare that they have no competing interests.

\section{Publisher's Note}

Springer Nature remains neutral with regard to jurisdictional claims in published maps and institutional affiliations.

\section{Author details \\ ${ }^{1}$ Faculty of Arts and Sciences, Queen's University, Kingston, Canada. Religion, Queen's University, Kingston, Canada. \\ Received: 9 October 2018 Accepted: 20 March 2019 \\ Published online: 29 March 2019} ${ }^{2}$ Department of Emergency Medicine, Queen's University, Kingston, Canada. ${ }^{3}$ Department of Public Health Sciences, Queen's University, Kingston, Canada. ${ }^{4}$ ABAAD Resource Center for Gender Equality, Beirut, Lebanon. ${ }^{5}$ School of

\section{References}

Abu S (2013) Early marriage and harassment of Syrian refugee women and girls in Jordan. In: Amnesty Int https://www.amnesty.org/en/latest/campaigns/ 2013/09/early-marriage-and-harassment-of-syrian-refugee-women-and-girlsin-jordan/. Accessed 13 Aug 2016

Adaku A, Okello J, Lowry B et al (2016) Mental health and psychosocial support for South Sudanese refugees in northern Uganda: a needs and resource assessment. Confl Health 10. https://doi.org/10.1186/s13031-016-0085-6

Amnesty International (2016) Why do refugee women from Syria in Lebanon face constant sexual harassment and exploitation? | Amnesty International. In: Amnesty Int https://www.amnesty.org/en/latest/campaigns/2016/02/whyrefugee-women-syria-lebanon-face-sexual-harassment-exploitation/. Accessed 21 Nov 2017

Bakhache N, Michael S, Roupetz S et al (2017) Global Health Action Implementation of a SenseMaker ${ }^{\circledR}$ research project among Syrian refugees in Lebanon Implementation of a SenseMaker ${ }^{\oplus}$ research project among Syrian refugees in Lebanon. Glob Health Action 10. https://doi.org/10.1080/ 16549716.2017 .1362792

Bartels S, Hamill K (2014) Running out of time: survival of Syrian refugee children in Lebanon. In: FXB Cent. Heal. Hum. Rights http://fxb.harvard.edu/fxb-reportsurvival-syrian-refugee-children-lebanon/. Accessed 7 Dec 2015

Bartels S, Michael S, Roupetz S et al (2018) Making sense of child, early and forced marriage among Syrian refugee girls: a mixed methods study in Lebanon. BMJ Glob Heal 3:e000509. https://doi.org/10.1136/bmjgh-2017000509

Bender K, Thompson SJ, Mcmanus $\mathrm{H}$ et al (2007) Capacity for survival: exploring strengths of homeless street youth. Child Youth Care Forum 36:25-42. https://doi.org/10.1007/s10566-006-9029-4

Brough M, Gorman D, Ramirez E, Westoby P (2003) Young refugees talk about well-being: a qualitative analysis of refugee youth mental health from three states. Aust J Soc Issues 38:193-208. https://doi.org/10.1002/j.1839-4655.2003. tb01142.x

Brough M, Schweitzer R, Shakespeare-Finch J et al (2013) Unpacking the micromacro nexus: narratives of suffering and hope among refugees from Burma recently settled in Australia. J Refug Stud 26:207-225. https://doi.org/10.1093/ jrs/fes025

Cherri Z, Gonzalez PA, Delgado RC (2016) The Lebanese-Sryain crisis: impact of influx of Syrian refugees to an already weak state. Risk Manag Healthc Policy 9:165-172. https://doi.org/10.2147/RMHP.S106068

Cognitive Edge (2017) SenseMaker. http://cognitive-edge.com/sensemaker/. Accessed 29 Jan 2017
Global Communities - Partners for Good (2013) Syrian refugee crisis - global communities rapid needs assessment. data.unhcr.org/syrianrefugees/ download.php?id=3752\%0A. Accessed 22 Nov 2017

Government of Lebanon, United Nations (2018) Lebanon Crisis Response Plan 2017 - 2020 (2018 update). In: Gov. Lebanon United Nations https://data2. unhcr.org/en/documents/download/63238. Accessed 18 Dec 2018

Guay J (2016) Social cohesion between Syrian refugees and urban host communities in Lebanon and Jordan. In: World Vis. Behalf Soc. Cohes. team Proj https://www.preparecenter.org/sites/default/files/social-cohesion-clean10th-nov-15.pdf. Accessed 21 Nov 2017

Hou W-L, Ko N-Y, Shu B-C (2016) Effects of a strengths-based perspective support group among Taiwanese women who left a violent intimate partner relationship. J Clin Nurs 25:543-554. https://doi.org/10.1111/jocn.13091

Human Rights Watch (2013) Lebanon: Women refugees from Syria harassed, exploited | human Rights Watch. Hum. Rights Watch https://www.hrw.org/ news/2013/11/26/lebanon-women-refugees-syria-harassed-exploited. Accessed 21 Nov 2017

Janmyr M (2016) Precarity in exile: the legal status of Syrian refugees in Lebanon. Refug Surv Q 35:58-78. https://doi.org/10.1093/rsq/hdw016

Kelley N, Durieux J-F (2004) UNHCR and current challenges in international refugee protection. Refug Canada's J Refug 22(1);6-17

Lynam T, Walker I (2016) Making sense of climate change: orientations to adaptation. Ecol Soc 21(4):17

Milne KMG (2015) Can sense-making tools inform adaptation policy? A practitioner's perspective. Ecol Soc 20:66. https://doi.org/10.5751/ES06791-200166

Pearce E, Mcmurray K, Walsh CA, Malek L (2017) Searching for tomorrow south Sudanese women reconstructing resilience through photovoice. Int Migr Integr 18:369-389. https://doi.org/10.1007/s12134-016-0500-2

Ravitch S, Mittenfelner Carl N (2015) Qualitative research: bridging the conceptual, theoretical, and methodological. Sage Publications, Inc, Thousand Oaks

Saldaña J (2012) The coding manual for qualitative researchers. SAGE Publications Ltd, London

Shakespeare-Finch J, Schweitzer RD, King J, Brough M (2014) Distress, coping, and posttraumatic growth in refugees from Burma. J Immigr Refug Stud 12: 311-330. https://doi.org/10.1080/15562948.2013.844876

Shakespeare-Finch J, Wickham K (2009) Adaptation of Sudanese refugees in an Australian context: investigating helps and hindrances. Int Migr 48. https:// doi.org/10.1111/j.1468-2435.2009.00561.x

Spencer D, Care International (2015) "To protect her honour": child marriage in emergencies - the fatal confusion between protecting girls and sexual violence. https://insights.careinternational.org.uk/publications/to-protect-herhonour-child-marriage-in-emergencies-the-fatal-confusion-betweenprotecting-girls-and-sexual-violence. Accessed 25 March 2019

Spencer R, Usta J, Essaid A et al (2015) Gender based violence against women and girls displaced by the Syrian conflict in South Lebanon and North Jordan: scope of violence and health correlates. Spanish Agency Int. Dev. Coop. UNFPA https://reliefweb.int/sites/reliefweb.int/files/resources/GBVAgainst-Women-and-Girl-Syrian-Refugees-in-Lebanon-and-Jordan-FINAL.pdf. Accessed 21 Nov 2017

Syrian Observatory For Human Rights (2017) About 475 thousand persons were killed in 76 months of the Syrian revolution and more than 14 million wounded and displaced. Syrian Obs. Hum. Rights http://www.syriahr.com/ en/?p=70012. Accessed 21 Nov 2017

The World Bank (2015) Syrian refugees living in Jordan and Lebanon: young female, at risk. In: World Bank Press Release http://www.worldbank.org/en/ news/press-release/2015/12/16/syrian-refugees-living-in-jordan-and-lebanoncaught-in-poverty-trap. Accessed 21 Nov 2017

Tippens J (2017) Urban Congolese refugees in Kenya: the contingencies of coping and resilience in a context marked by structural vulnerability. Qual Health Res 27:1090-1103. https://doi.org/10.1177/1049732316665348

UN Office of the High Commissioner for Human Rights (1989) Convention on the rights of the child. United Nations http://www.ohchr.org/en/ professionalinterest/pages/crc.aspx. Accessed 21 Nov 2016

UN Women (2013) Inter-agency AssGender-based violence and child protection among Syrian refugees in Jordan, with a focus on early marriage. http:// jordan.unwomen.org/en/digital-library/publications/2013/7/gender-basedviolence-and-childprotection-among-syrian-refugees-in-jordan. Accessed 15 May 2017

Ungar M, Brown M, Liebenberg L et al (2008) Unique pathways to resilience across cultures. Youth Stud Aust 42:287-310 
UNICEF (2014) Under siege: the devastating impact on children of three years of conflict in Syria. http://www.unicef.org/publications/index_72815.html. Accessed 7 Dec 2015

UNICEF (2017) Refugee children in crisis, are you aware of the challenges they face? UNICEF Connect https://blogs.unicef.org/blog/refugee-children-crisis/. Accessed 13 Feb 2018

United Nations High Commission for Refugees (2013) The future of Syria refugee children in crisis. UNHCR https://www.refworld.org/pdfid/529c3b4d4. pdf. Accessed 21 Nov 2017

Uppsala Conflict Data Program. (n.d.) Syria Number of Deaths. http://ucdp.uu.se/ \#/country/652. Accessed 18 Dec 2018

World Vision International (2012) Robbed of childhood, running from war. https:/www.wvi.org/justice-children/publication/robbed-childhood-runningwar from war FINAL UPDATED.Pdf. Accessed 15 May 2017

\section{Submit your manuscript to a SpringerOpen ${ }^{\circ}$ journal and benefit from:}

- Convenient online submission

- Rigorous peer review

- Open access: articles freely available online

High visibility within the field

- Retaining the copyright to your article

Submit your next manuscript at $\boldsymbol{\nabla}$ springeropen.com 